\title{
Posterior Chamber of the Eye
}

National Cancer Institute

\section{Source}

National Cancer Institute. Posterior Chamber of the Eye. NCI Thesaurus. Code C12900.

A space within the eye located between the iris and the lens. It is filled with aqueous humor. 